\title{
The Circadian Curve of Intraocular Pressure: Can We Estimate Its Characteristics during Office Hours?
}

\author{
Paolo Fogagnolo, ${ }^{1}$ Nicola Orzalesi, ${ }^{2}$ Antonio Ferreras, ${ }^{3,4}$ and Luca Rossetti ${ }^{2}$
}

Purpose. To verify whether office-hour measurements in patients in different body positions can estimate the characteristics of 24-hour intraocular pressure (IOP).

MeTHoDs. The 24-hour IOP curves of 29 healthy subjects (10 young adults, 19 elderly) and 30 patients with untreated glaucoma were analyzed. Measurements were taken at 9 AM; 12, 3, 6 , and $9 \mathrm{PM}$; and 12,3, and $6 \mathrm{AM}$, both in the supine and sitting (Goldmann tonometer) positions. Peak, mean, and fluctuation of 24-hour IOP curves were compared with office-hour measurements obtained in subjects in the sitting position alone and with combined pressures obtained in the sitting and supine positions (four measurements in each body position from $9 \mathrm{AM}$ to $6 \mathrm{PM})$. The percentage of subjects with estimates of all IOP parameters within a cutoff of \pm 1 (peak and mean) and $\pm 2 \mathrm{~mm}$ $\mathrm{Hg}$ (fluctuation) was calculated.

Results. Office-hour sitting measurements correctly identified peak, mean, and IOP fluctuation in $10 \%$ of the young adults, $32 \%$ of the elderly control subjects, and $20 \%$ of the patients with glaucoma, whereas the combination of supine and sitting measurements correctly identified them in $30 \%, 85 \%$, and $46 \%$ of cases, respectively. It is noteworthy that office-hour measurements did not characterize any 24-hour parameter in $20 \%$ of patients with glaucoma.

Concuusions. Compared with sitting measurements alone, the collection of supine and sitting office-hour measurements may enhance the correct identification of 24-hour IOP characteristics in both control subjects and untreated patients with glaucoma, thus reducing the need for obtaining 24-hour curves to a minority of patients. (Invest Ophthalmol Vis Sci. 2009;50: 2209-2215) DOI:10.1167/iovs.08-2889

$I^{2}$ ntraocular pressure (IOP) is the main risk factor for the development and the progression of glaucoma, ${ }^{1-4}$ whereas the role of IOP fluctuation as an independent risk factor has been the object of a very limited number of studies ${ }^{1,5-8}$ whose results are controversial.

Apart from the differences in the study designs and populations, the methods to analyze the IOP dataset may have influenced the results, ${ }^{9}$ as few studies ${ }^{1,7,8}$ calculated the long-

From the ${ }^{1} \mathrm{G}$. B. Bietti Foundation-IRCCS (Istituto di Ricovero e Cura a Carattere Scientifico), Rome, Italy; the ${ }^{2}$ Eye Clinic, Department of Medicine, Surgery and Odontoiatry, San Paolo Hospital, University of Milan, Milan, Italy; ${ }^{3}$ Miguel Servet University Hospital, Zaragoza, Spain; and the ${ }^{4}$ University of Zaragoza, Zaragoza, Spain.

Presented in part at the annual meeting of the Association for Research in Vision and Ophthalmology, Fort Lauderdale, Florida, AprilMay 2008.

Submitted for publication September 16, 2008; revised October 30 and November 27, 2008; accepted March 17, 2009.

Disclosure: P. Fogagnolo, None; N. Orzalesi, None; A. Ferreras, None; L. Rossetti, None

The publication costs of this article were defrayed in part by page charge payment. This article must therefore be marked "advertisement" in accordance with 18 U.S.C. $\$ 1734$ solely to indicate this fact.

Corresponding author: Paolo Fogagnolo, Eye Clinic, San Paolo Hospital, Via di Rudini 8, 20142 Milano, Italy;

fogagnolopaolo@googlemail.com. term IOP fluctuation from a series of single IOP measurements during consecutive visits, and others ${ }^{5,6}$ calculated the shortterm IOP fluctuation from diurnal curves. None of the studies conducted to demonstrate the influence of IOP fluctuation on the progression of glaucoma was based on measurements taken during a 24-hour period (nyctohemeral IOP phasing).

Twenty-four hour phasing is the most precise procedure for measuring the characteristics (mean, peak, fluctuation) of an IOP curve. Although in most clinical settings the management of patients with glaucoma relies only on single IOP measurements or, less often, on office-hour curves, the clinical relevance of 24-hour IOP data has been acknowledged, ${ }^{10-13}$ as the nocturnal period may be crucial in glaucoma because of several factors (increase in IOP due to elevation of episcleral venous pressure, redistribution of body fluids occurring in the recumbent position, ${ }^{14}$ and decrease in blood pressure ${ }^{15,16}$ ) and because of the different efficacy of IOP-lowering treatments ${ }^{16,17}$ due to changes in receptor activity. Yet, 24-hour curves are impractical and expensive, and in general they can be performed only in small groups of subjects in a very limited number of institutions worldwide.

The more practical option of using office-hour data to predict the behavior of 24-hour IOP (thus limiting the practical interest of nyctohemeral evaluations) has been explored in few studies $^{12,18-20}$ that showed that mean office- and 24-hour IOPs are similar (in both treated and untreated patients with glaucoma), but office-hour data significantly underestimate IOP fluctuation. It is likely that this inability to correctly assess IOP fluctuation mostly derives from the underestimation of the 24-hour peak, which would occur outside office hours in up to two thirds of cases. ${ }^{10}$ These findings, based on sitting-position measurements alone, have been challenged by results in a recent study ${ }^{21}$ that suggest that peak IOP (and indirectly, IOP fluctuation) could be calculated by office-hour IOP readings taken in the supine position.

The purpose of our study was to verify whether IOP measurements taken in different body positions during office hours can be used to extrapolate the characteristics of 24-hour IOP curves of healthy subjects and patients with glaucoma.

\section{Methods}

This study was a retrospective analysis of the 24-hour IOP curves in normal subjects and subjects with glaucoma participating in previous studies by our group. ${ }^{17,22,23}$ It was conducted at the Eye Clinic of San Paolo Hospital, University of Milan, Italy, after approval by the local Ethics Committee and according to the tenets of the Declaration of Helsinki and national laws for the protection of personal data. Informed consent was obtained from all the participants in the study.

\section{Study Population}

We analyzed data from 30 patients with glaucoma (age: $71 \pm 7$ years, $\mathrm{F} / \mathrm{M}=18 / 12$ ) and 29 control subjects. The control group included both young adult (age, $<30$ years) and elderly ( $>65$ years) subjects, and these populations were analyzed separately because they previously showed differences in 24-hour IOP and blood pressure curves ${ }^{17}$; 10 young adult (age: $25 \pm 4$ years, $\mathrm{F} / \mathrm{M}=6 / 4$ ), and 19 elderly subjects (age: $69 \pm 4$ years, $\mathrm{F} / \mathrm{M}=10 / 9$ ) were therefore considered. 
To be included in the study, patients had to have glaucomatous visual fields (abnormal mean defect and corrected pattern standard deviation on at least two consecutive, reliable Humphrey 30-2 fullthreshold tests), optic nerve head $(\mathrm{ONH})$ changes (presence of concentric enlargement of the optic cup, localized notching, or both, as evaluated by means of color stereophotographs), ${ }^{24}$ and/or retinal nerve fiber layer (RNFL) defects (presence of focal or diffuse neuroretinal rim thinning, as evaluated by means of a scanning laser ophthalmoscope $^{25}$ ). Patients with ocular hypertension were excluded. Normal subjects had age $>18$ years, IOP $<21 \mathrm{~mm} \mathrm{Hg}$ (as measured on two consecutive occasions separated by an interval of at least 2 hours but not more than 12 weeks), normal perimetry results, and normal $\mathrm{ONH}$ and RNFL (diagnosed as just described).

Exclusion criteria included baseline untreated IOP $>30 \mathrm{~mm} \mathrm{Hg}$, angle-closure glaucoma, secondary glaucomas, corneal abnormalities preventing reliable IOP measurement, previous filtration surgery, having one eye, pregnancy, significant disturbances of wake-sleep rhythms, and/or the regular use of hypnotic drugs reported by the patients. Eligibility was verified by means of a complete ophthalmic assessment.

\section{Twenty-Four-Hour IOP Evaluation}

All subjects underwent generation of a single 24-hour IOP curve by measurements in both the supine and sitting positions. The patients with POAG who were in medical treatment at the moment of enrollment underwent a washout period of at least 4 weeks.

The method of recording 24-hour IOP curves has been described in detail. ${ }^{17}$ A summary of the procedures follows. The patients were hospitalized in the morning (at $7 \mathrm{AM}$ ) and stayed for the following 24 hours. The awake period lasted from approximately 6:30 AM to 11:00 PM. Intraocular pressure was measured at 3, 6, and 9 AM; 12, 3, 6, and $9 \mathrm{PM}$; and $12 \mathrm{AM}$. For the daytime measurements (9 AM-9 PM), patients were asked to go to bed and relax for approximately 15 minutes, after which supine IOP was measured in both eyes. After approximately 10 minutes, a second IOP value was measured at the slit lamp. During the night, the patients were awakened approximately 10 minutes before measurement to prevent a sudden increase in IOP. The IOP measurements were made with a handheld electronic tonometer (TonoPen XL; Bio-Rad, Glendale, CA) with the patient supine and a Goldmann applanation tonometer with the patient sitting at the slit lamp. Every measurement by TonoPen XL consisted of a variable number of readings until the coefficient of variation was less than $5 \%$. All measurements were taken at each time point by two well-trained glaucoma specialists who had obtained good accordance between their measurements ( $\kappa=0.82$ with both tonometers). If the measurements differed by $>2 \mathrm{~mm} \mathrm{Hg}$, a third measurement was taken; the mean of two or the median of three recordings was used for the analysis. If both eyes were eligible, only one eye (chosen at random) was used in the analysis.

\section{Statistical Analysis}

All statistical analyses were calculated with commercial software (SPSS, (ver. 15.0; SPSS Inc., Chicago, IL).

For the purposes of the study, we considered the 24-hour curves obtained in habitual body position-that is sitting readings during waking time (from 9 AM to 9 PM) and supine readings during night time (from 12 to $6 \mathrm{AM}$ ). These curves were compared to the readings of the same 24-hour curves obtained during office hours (from 9 AM to $6 \mathrm{PM})$ in both supine and sitting positions.

The objectives of the study were as follows. We first analyzed the ability of different criteria to predict peak IOP from office-hour readings. Thereafter, we tested the ability of office-hour measurements (in sitting position or in supine position only, or combining sitting and supine positions), to estimate mean 24-hour IOP and its fluctuation; the advantage of adding the peak estimate to the above data was also evaluated. Finally, we addressed the clinical impact of using the best criterion instead of sitting measurements alone by calculating, for each study group, the percentage of patients whose IOP curve was correctly characterized (i.e., mean, peak and fluctuation falling within cutoff values of $\pm 1, \pm 1$, and $\pm 2 \mathrm{~mm} \mathrm{Hg}$ respectively from the 24-hour data).

\section{Peak IOP}

Five parameters were tested in their ability of extrapolating peak IOP from office-hour readings:

1. The highest value obtained from the office-hour curve in the sitting position.

2. The formula proposed by Mosaed et al. ${ }^{21}$ based on office-hour supine IOP (peak IOP $=5.98+0.771 \times$ average office-hour supine IOP).

3. The formula proposed by Mosaed et al. ${ }^{21}$ based on office-hour sitting IOP $($ peak IOP $=12.04+0.616 \times$ average office-hour sitting IOP).

4. The mean of values obtained with the previous two formulas.

5. The highest value obtained from the office-hour curve in both supine and sitting positions.

The following parameters were then calculated: mean and range of the difference between estimate and 24-hour peak IOP (expressed as absolute values, i.e., both an underestimation of $-4 \mathrm{~mm} \mathrm{Hg}$ and an overestimation of $+4 \mathrm{~mm} \mathrm{Hg}$ counting as $4 \mathrm{~mm} \mathrm{Hg}$ ), the percentage of patients with IOP falling within $\pm 1 \mathrm{~mm} \mathrm{Hg}$ from the 24-hour peak, and the $R^{2}$ between the estimate and the 24-hour value.

The differences obtained for each parameter were tested versus office-hour readings ( $t$-test for paired data), to detect the best criterion, which was set in the presence of (1) the minor absolute difference or (in case of identical results), (2) the highest percentage of patients with IOP within $\pm 1 \mathrm{~mm} \mathrm{Hg}$ from the peak, or (3) the highest $R^{2}$.

\section{Mean IOP and IOP Fluctuations}

The 24-hour mean IOP and IOP fluctuations in habitual body position were compared to those calculated from:

1. Office-hour readings only in the sitting position (four measurements).

2. Office-hour readings only in the supine position (four measurements).

3. Office-hour sitting readings (four measurements) + the peak IOP, as estimated with the better of the previous formulas.

4. A combination of sitting and supine office-hour readings (four + four measurements).

5. A combination of sitting and supine office-hour readings (four + four measurements) + the estimated peak IOP.

IOP fluctuation was expressed both as range and standard deviation. We calculated the mean and range of the difference between the estimated and 24-hour values (expressed as absolute values), the percentages of patients having IOP falling within \pm 1 (mean IOP) and \pm 2 (IOP fluctuation) $\mathrm{mm} \mathrm{Hg}$ from 24-hour readings, and $R^{2}$. The best criterion was defined as just described.

\section{Results}

Twenty-four-hour IOP curves in habitual body position are given in Figure 1 (mean values of normal subjects and patients with glaucoma), and mean data for mean IOP, peak, and fluctuation are shown in Table 1. Mean IOP was higher in the patients with glaucoma in comparison to the healthy subjects $(P<0.001, t$-test for unpaired data) and in the healthy elderly subjects in comparison to the young control subjects $(P=$ 0.01 ). IOP peaked outside office hours in $91 \%$ of the young control subjects, $62 \%$ of the elderly control subjects, and $42 \%$ of the patients with POAG. When expressed as the range of IOP measurements, IOP fluctuation was higher in the patients with glaucoma $(9.3 \pm 3.2 \mathrm{~mm} \mathrm{Hg})$ than in the young, healthy subjects $(7.3 \pm 3.2 \mathrm{~mm} \mathrm{Hg}, P=0.02, t$-test for paired data) and 


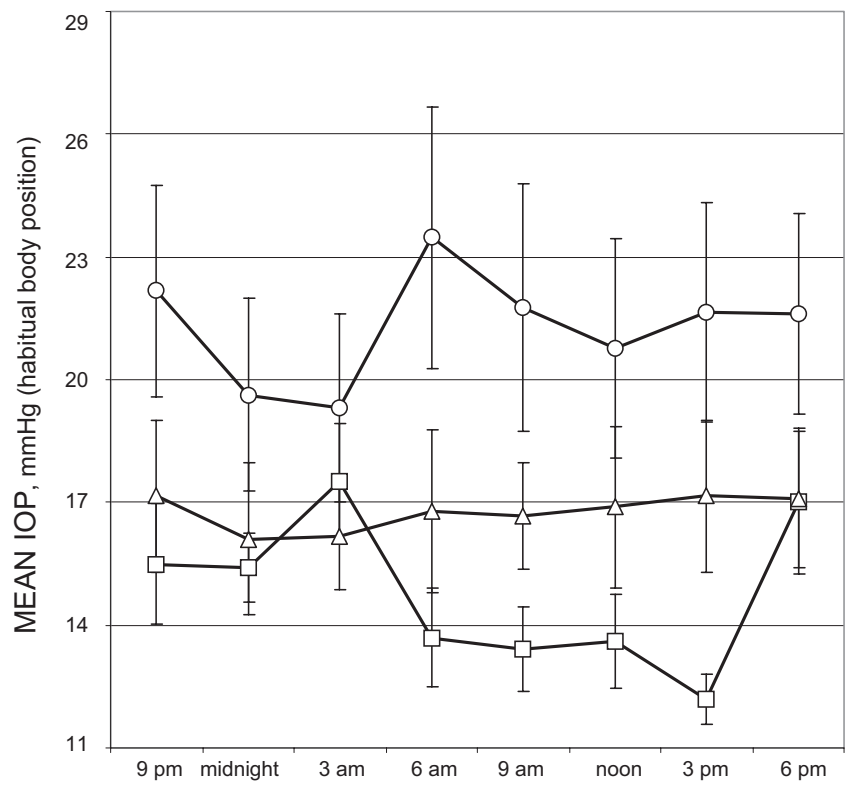

FIGURE 1. Mean 24-hour IOP curves in subjects in habitual body position. $(\square)$ Young healthy subjects; $(\triangle)$ elderly healthy subjects; $(\bigcirc)$, patients with glaucoma.

the elderly subjects $(7.5 \pm 2.3 \mathrm{~mm} \mathrm{Hg}, P=0.05)$. No statistically significant differences were found when fluctuation was expressed as the standard deviation of IOP measurements.

Table 2 summarizes the estimates of peak IOP. The mean of the two formulas by Mosaed et al. $^{21}$ for supine and sitting measurements achieved the best results in the young healthy subjects (mean deviation of 1.9 compared with 3.9 for sitting measurements, $P>0.05$, with a correct peak quantification in $50 \%$ of cases). The best estimate in the elderly control subjects was the highest reading between the supine and sitting measurements, but it provided a small improvement over the results obtained by sitting readings alone (mean deviation, 1.4 vs. $1.5, P>0.05$; correct quantification of the peaks in $58 \% \mathrm{vs}$. $53 \%$ of cases). In the patients with glaucoma, the highest office-hour reading in the sitting position was the best estimate; it correctly quantified $70 \%$ of peaks, with a mean difference of $1.3 \mathrm{~mm} \mathrm{Hg}$ compared with the 24-hour dataset ( $P \leq$ 0.05 compared with the formulas by Mosaed et al. ${ }^{21}$ ).

The data on the prediction of mean 24-hour IOP and IOP fluctuation are given in Tables 3 and 4, respectively.

In young control subjects, the best prediction of these two parameters was obtained by combining the office-hour sitting dataset to the peak estimate. The estimate of mean IOP differed by $0.6 \mathrm{~mm} \mathrm{Hg}$ from the 24-hour value $\left(R^{2}=0.79\right)$, and significantly improved (by $1.0 \mathrm{~mm} \mathrm{Hg}$ ) the estimate obtained by sitting readings alone $(P=0.001)$. Also, $80 \%$ of subjects had mean IOP correctly estimated, compared with only $20 \%$ for office-hour sitting readings. Using this criterion, we also obtained a good estimate of IOP fluctuation (deviation of $1.9 \mathrm{~mm}$ $\mathrm{Hg} ; R^{2}=0.36$ ), with a relevant, though not statistically significant, improvement of $2.2 \mathrm{~mm} \mathrm{Hg}$ compared with the officehour sitting dataset; $60 \%$ of subjects had an estimate that fell within $\pm 2 \mathrm{~mm} \mathrm{Hg}$ from the 24-hour value.

The combination of supine and sitting office-hour IOP measurements provided the best estimates of mean IOP and its fluctuation in both the elderly control subjects and the patients with glaucoma, whereas no significant advantage derived from the calculation of the peak estimation.

In the elderly control subjects, the best criterion improved mean IOP and IOP fluctuation by $0.5(P>0.05)$ and $1.3(P=$ $0.03) \mathrm{mm} \mathrm{Hg}$ compared with office-hour sitting measurements. The deviation from mean 24-hour IOP was $0.7 \mathrm{~mm} \mathrm{Hg}$, with good correlation $\left(R^{2}=0.89\right) ; 79 \%$ of cases were within \pm 1 $\mathrm{mm} \mathrm{Hg}$ from 24-hour mean IOP. The deviation from 24-hour IOP fluctuation was $1.6 \mathrm{~mm} \mathrm{Hg}$ and, again, $79 \%$ of cases fell within $\pm 2 \mathrm{~mm} \mathrm{Hg}$ from the actual value. The correlation between office- and 24-hour measurements was only moderate $\left(R^{2}=0.43\right)$.

In the glaucoma group, when compared to sitting measurements alone, supine and sitting office-hour readings provided a negligible advantage of $0.1 \mathrm{~mm} \mathrm{Hg}$ in the mean 24-hour IOP estimate, which corresponded to a $10 \%$ improvement (from $40 \%$ to $50 \%$ ) in the proportion of patients within $\pm 1 \mathrm{~mm} \mathrm{Hg}$ from the 24-hour value; an excellent $R^{2}$ was found with both parameters (0.92). On the contrary, a considerable improvement of $1.4 \mathrm{~mm} \mathrm{Hg}$ in the fluctuation estimate was found, and this corresponded to a $20 \%$-improvement (from $30 \%$ to $50 \%$ ) in the proportion of patients having IOP fluctuation correctly estimated. Of note, the correlation between 24-hour IOP fluctuation and all office-hour estimates was very weak $\left(R^{2}=\right.$ $0.03-0.15$ ), due to the very large discrepancy between predicted and actual fluctuation between individuals (ranges between -8 and $+11 \mathrm{~mm} \mathrm{Hg}$ were found for the best-fitting criterion).

The clinical advantage of measuring supine IOP during office hours is shown in Table 5. While sitting office-hour measurements correctly identified the characteristics of the 24-hour curves (mean, peak, fluctuation) in only $10 \%$ of the young control subjects, $32 \%$ of the elderly control subjects, and $20 \%$ of the patients with POAG, these percentages, respectively, increased to $30 \%, 85 \%$, and $46 \%$ when supine measure-

TABLE 1. The 24-Hour IOP Data in Habitual Body Position

Timing of Peaks

\begin{tabular}{|c|c|c|c|c|c|}
\hline & $\begin{array}{c}\text { IOP, } \\
\text { Mean (SD) }\end{array}$ & $\begin{array}{l}\text { IOP Fluctuation, } \\
\text { Mean (SD) }\end{array}$ & $\begin{array}{l}\text { IOP Fluctuation, } \\
\text { Mean (SD) }\end{array}$ & $\begin{array}{l}\text { During Office } \\
\text { Hours (\%) }\end{array}$ & $\begin{array}{c}\text { Outside Office } \\
\text { Hours (\%) }\end{array}$ \\
\hline Young control subjects & $14.8(1.4)$ & $7.3(3.2)$ & $2.6(1.0)$ & 9 & 91 \\
\hline Range & $13.0-16.6$ & $2.0-12.0$ & $1.0-4.1$ & & \\
\hline Elderly control subjects & $16.8(2.4)^{*}$ & $7.5(2.3)$ & $2.7(0.8)$ & 38 & 62 \\
\hline Range & $11.4-22.1$ & $4.0-11.0$ & $1.4-4.2$ & & \\
\hline Patients with glaucoma & $21.3(4.5) \dagger$ & $9.3(3.2) \ddagger$ & $3.1(1.2)$ & 58 & 42 \\
\hline Range & $15.0-32.6$ & $2.0-16.0$ & $0.9-6.3$ & & \\
\hline
\end{tabular}

Subjects with the same peak IOP value during and outside office hours were counted twice.

${ }^{*}$ Healthy young subjects versus elderly control subjects, $P=0.01$

† Glaucoma versus young control subjects, $P<0.001$; glaucoma versus elderly control subjects, $P<0.001$.

‡ Glaucoma versus young control subjects, $P=0.05$; glaucoma versus elderly control subjects, $P=0.02$. 


\begin{tabular}{|c|c|c|c|c|c|}
\hline & $\begin{array}{l}\text { Office-Hour } \\
\text { Sitting Position }\end{array}$ & $\begin{array}{l}\text { Mosaed's } \\
\text { Formula }^{21} \text { for } \\
\text { Supine Position }\end{array}$ & $\begin{array}{l}\text { Mosaed's } \\
\text { Formula }^{21} \text { for } \\
\text { Sitting Position }\end{array}$ & $\begin{array}{l}\text { Mean of Mosaed's } \\
\text { Formulas }^{21}\end{array}$ & $\begin{array}{l}\text { Sitting+Supine } \\
\text { Office-Hour } \\
\text { Readings }\end{array}$ \\
\hline \multicolumn{6}{|l|}{ Young control subjects } \\
\hline $\begin{array}{l}\text { Difference from 24-hour data (absolute } \\
\text { value), } \mathrm{mm} \mathrm{Hg}^{*}\end{array}$ & $3.9(2.7)$ & $2.1(1.5)$ & $2.1(1.9)$ & $1.9(1.6)$ & $3.3(3.0)$ \\
\hline $\begin{array}{l}\text { Percentage of cases falling within } \pm 1 \\
\mathrm{~mm} \mathrm{Hg} \text { from } 24 \text {-hour peak IOP }\end{array}$ & $30 \%$ & $40 \%$ & $50 \%$ & $50 \%$ & $30 \%$ \\
\hline$R^{2}$ & 0.18 & 0.27 & 0.26 & 0.32 & 0.27 \\
\hline \multicolumn{6}{|l|}{ Elderly control subjects } \\
\hline $\begin{array}{l}\text { Difference from 24-hour data (absolute } \\
\text { value), } \mathrm{mm} \mathrm{Hg}^{*}\end{array}$ & $1.5(1.6)$ & $2.0(2.2)$ & $2.2(1.5)$ & $1.7(1.2)$ & $1.4(1.6)$ \\
\hline $\begin{array}{l}\text { Percentage of cases falling within } \pm 1 \\
\text { mm Hg from 24-hour peak IOP } \\
R^{2}\end{array}$ & $\begin{array}{l}53 \% \\
0.77\end{array}$ & $\begin{array}{l}42 \% \\
0.27\end{array}$ & $\begin{array}{l}26 \% \\
0.76\end{array}$ & $\begin{array}{l}37 \% \\
0.73\end{array}$ & $\begin{array}{l}58 \% \\
0.64\end{array}$ \\
\hline \multicolumn{6}{|l|}{ Patients with glaucoma } \\
\hline $\begin{array}{l}\text { Difference from 24-hour data (absolute } \\
\text { value), } \mathrm{mm} \mathrm{Hg}^{*}\end{array}$ & $1.3(2.6)$ & $3.0(2.8) \dagger$ & $2.6(1.8) \ddagger$ & $2.6(2.2) \S$ & $2.3(2.9)$ \\
\hline $\begin{array}{l}\text { Percentage of cases falling within } \pm 1 \\
\text { mm Hg from } 24 \text {-hour peak IOP }\end{array}$ & $70 \%$ & $30 \%$ & $23 \%$ & $30 \%$ & $53 \%$ \\
\hline$R^{2}$ & 0.82 & 0.67 & 0.78 & 0.79 & 0.70 \\
\hline
\end{tabular}

Bold boxes indicate the best formula for each study group.

*Values are mean (SD).

$\dagger P=0.02 ; \ddagger P=0.05 ; \rrbracket P=0.03$, all versus office-hour sitting IOP.

ments were also considered. Yet, using all possible criteria, it was still impossible to predict any of the characteristics of the 24-hour curves in $40 \%, 5 \%$, and $20 \%$ of cases, respectively.

\section{Discussion}

Our study results suggest that supine measurements during office hours can improve the estimate of the characteristics of the 24-hour IOP curve in patients with glaucoma and in control subjects.

The inadequacy of office-hour sitting readings in patients with severe or progressing glaucoma has been shown by Barkana et al. ${ }^{10}$ : nearly $70 \%$ of peak IOP were lost and fluctuations were underestimated by a mean of $3 \mathrm{~mm} \mathrm{Hg}$. Similar results were obtained in other studies showing IOP peaking outside office hours in $52 \%$ to $66 \%$ of cases. ${ }^{12,13,20}$ Our dataset for patients with glaucoma confirms these findings, even if peak IOP was correctly identified in $70 \%$ of cases, as sitting readings provided inadequate measures of mean IOP and IOP fluctuation in $60 \%$ and $70 \%$ of cases, respectively (with mean underestimations of 1.5 and $4.4 \mathrm{~mm} \mathrm{Hg}$ ). Overall, using office-hour sitting measurements, only $20 \%$ of patients with glaucoma received a correct identification of all their curve parameters (peak, mean, and fluctuation).

Mosaed et al. ${ }^{21}$ suggested that IOP assessment could be improved by using a formula to predict the peak IOP (and, indirectly, IOP fluctuations) from office-hour readings in a group of untreated patients with glaucoma. Our data confirm that such an estimate can be calculated on the basis of officehour measurements, although this procedure induced significant advantages only in the group of young adult control subjects.

TABLE 3. Mean IOP Estimates

\begin{tabular}{|c|c|c|c|c|c|}
\hline & Sitting & Supine & Sitting+Supine & Sitting $+\mathbf{P E}$ & Sitting + Supine $+\mathrm{PE}$ \\
\hline \multicolumn{6}{|l|}{ Young control subjects } \\
\hline $\begin{array}{l}\text { Difference from 24-hour data (absolute } \\
\text { value), } \mathrm{mm} \mathrm{Hg}^{*}\end{array}$ & $1.6(0.7)$ & $2.5(2.1)$ & $1.1(0.7)$ & $0.6(0.4) \dagger$ & $1.2(0.9)$ \\
\hline $\begin{array}{l}\text { Percentage of cases falling within } \pm 1 \\
\text { mm Hg from } 24 \text {-hour mean IOP } \\
R^{2}\end{array}$ & $\begin{array}{l}20 \% \\
0.77\end{array}$ & $\begin{array}{l}40 \% \\
0.39\end{array}$ & $\begin{array}{l}60 \% \\
0.63\end{array}$ & $\begin{array}{l}80 \% \\
0.79\end{array}$ & $\begin{array}{l}40 \% \\
0.63\end{array}$ \\
\hline \multicolumn{6}{|l|}{ Elderly control subjects } \\
\hline $\begin{array}{l}\text { Difference from } 24 \text {-hour data (absolute } \\
\text { value), mm } \mathrm{Hg}^{*} \\
\text { Percentage of cases falling within } \pm 1\end{array}$ & $1.2(0.8)$ & $1.7(1.2)$ & $0.7(0.5)$ & $0.9(1.2)$ & $0.8(0.7)$ \\
\hline $\mathrm{mm} \mathrm{Hg}$ from 24-hour mean IOP & $63 \%$ & $37 \%$ & $79 \%$ & $58 \%$ & $53 \%$ \\
\hline$R^{2}$ & 0.76 & 0.42 & 0.89 & 0.80 & 0.89 \\
\hline \multicolumn{6}{|l|}{ Patients with glaucoma } \\
\hline $\begin{array}{l}\text { Difference from 24-hour data (absolute } \\
\text { value), } \mathrm{mm} \mathrm{Hg}^{*}\end{array}$ & $1.5(1.0)$ & $2.3(1.6)$ & $1.4(1.0)$ & $1.4(1.1)$ & $1.6(1.0)$ \\
\hline $\begin{array}{l}\text { Percentage of cases falling within } \pm 1 \\
\text { mm Hg from } 24 \text {-hour mean IOP }\end{array}$ & $40 \%$ & $33 \%$ & $50 \%$ & $43 \%$ & $33 \%$ \\
\hline 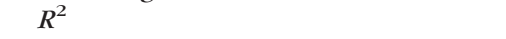 & 0.92 & 0.77 & 0.92 & 0.93 & 0.92 \\
\hline
\end{tabular}

PE, peak IOP estimate. Bold boxes indicate the best formula for each study group.

* Values are mean (SD).

$\dagger P=0.001$ versus office-hour sitting IOP. 
TABLE 4. Estimates of IOP Fluctuation

\begin{tabular}{|c|c|c|c|c|c|}
\hline & Sitting & Supine & Sitting+Supine & Sitting $+P E$ & Sitting + Supine $+P E$ \\
\hline \multicolumn{6}{|l|}{ Young control subjects } \\
\hline $\begin{array}{l}\text { Difference from 24-hour data (absolute } \\
\text { value), } \mathrm{mm} \mathrm{Hg}^{*}\end{array}$ & $4.1(2.9)$ & $2.8(2.7)$ & $3.3(3.0)$ & $1.9(1.8)$ & $3.3(2.9)$ \\
\hline $\begin{array}{l}\text { Percentage of cases falling within } \pm 2 \\
\mathrm{~mm} \mathrm{Hg} \text { from 24-hour IOP }\end{array}$ & & & & & \\
\hline fluctuation & $40 \%$ & $70 \%$ & $40 \%$ & $60 \%$ & $30 \%$ \\
\hline$R^{2}$ & 0.17 & 0.06 & 0.14 & 0.36 & 0.14 \\
\hline \multicolumn{6}{|l|}{ Elderly control subjects } \\
\hline $\begin{array}{l}\text { Difference from } 24 \text {-hour data (absolute } \\
\text { value), } \mathrm{mm} \mathrm{Hg}^{*}\end{array}$ & $2.9(2.0)$ & $3.3(2.8)$ & $1.6(1.5) \dagger$ & $1.6(1.5)$ & $1.7(1.4)$ \\
\hline $\begin{array}{l}\text { Percentage of cases falling within } \pm 2 \\
\text { mm Hg from 24-hour IOP }\end{array}$ & & & & & \\
\hline fluctuation & $42 \%$ & $53 \%$ & $79 \%$ & $63 \%$ & $85 \%$ \\
\hline$R^{2}$ & 0.30 & 0.00 & 0.43 & 0.23 & 0.36 \\
\hline \multicolumn{6}{|l|}{ Patients with glaucoma } \\
\hline $\begin{array}{l}\text { Difference from 24-hour data (absolute } \\
\text { value), } \mathrm{mm} \mathrm{Hg} \mathrm{Hg}^{*} \\
\text { Percentage of cases falling within } \pm 2 \\
\text { mm Hg from 24-hour IOP }\end{array}$ & $4.4(3.3)$ & $4.1(3.2)$ & $3.0(3.1) \ddagger$ & $3.1(2.8)$ & $3.1(3.1)$ \\
\hline fluctuation & $30 \%$ & $33 \%$ & $50 \%$ & $53 \%$ & $50 \%$ \\
\hline$R^{2}$ & 0.15 & 0.03 & 0.08 & 0.13 & 0.06 \\
\hline
\end{tabular}

PE, peak IOP estimate. Bold boxes indicate the best formula for each study group.

*Values are mean (SD).

$\dagger P=0.03$ versus office-hour sitting IOP.

$\ddagger P=0.05$ versus office-hour sitting IOP.

On the contrary, the relatively simpler addition of officehour supine IOP readings to sitting measurements proved to be a good strategy for determining the 24-hour IOP characteristics (mean, peak, fluctuation) in the patients with glaucoma and in the elderly healthy population.

In the patients with glaucoma, these estimates allowed a correct identification of mean IOP and IOP fluctuation in 50\% of cases; the improvement in determining IOP fluctuation was statistically significant compared with sitting measurements alone. This strategy was also more precise in the elderly control subjects: mean IOP and IOP fluctuation were correctly detected in $79 \%$ of cases and, again, the improvement for IOP fluctuation was statistically significant compared with the sitting measurements alone. Overall, by means of this strategy, it was possible to correctly characterize the peak, mean, and fluctuation of the 24-hour curves of $46 \%$ of the patients with glaucoma and $85 \%$ of the elderly control subjects compared with $20 \%$ and $32 \%$, respectively, when the sitting measurements alone were used (Table 5).

Our analyses also highlight that it was impossible to predict any of the characteristics of the 24-hour curve by means of office-hour measurements in $20 \%$ of the glaucoma cases and that in $23 \%$ of the cases the addition of supine office-hour reading was only partially useful. In these cases, a 24-hour IOP evaluation would still be necessary. In any event, caution should be used when extending the use of our results to the general population: in our dataset, a poor correlation between 24-hour and office-hour measurements for IOP fluctuations was found ( $R^{2}$ ranging from 0 to 0.43 ), as some patients obtained large deviations from the actual 24-hour fluctuation (ranging from -8 to $+11 \mathrm{~mm} \mathrm{Hg}$ ).

As a general rule, the results of the studies on 24-hour IOP should be considered with caution because of several intrinsic potential biases that could limit their generalization-in particular hospitalization, disturbed sleep, and exposure to light during the measurements made at night. ${ }^{26,27}$ Peak IOP, when occurring during the night, may not reflect the physiological 24-hour rhythm because of a well-described increase in IOP because of sudden waking ${ }^{26}$; we therefore tried to protect our results from this effect by measuring IOP 10 minutes after awakening.

TABLE 5. The Clinical Impact of the Use of a Combination of Supine and Sitting Measurements during Office Hours: Improvement in the Characterization of the 24-Hour Curve Using Different Criteria

\begin{tabular}{|c|c|c|c|}
\hline & $\begin{array}{c}\text { Young } \\
\text { Control } \\
\text { Subjects }\end{array}$ & $\begin{array}{l}\text { Elderly } \\
\text { Control } \\
\text { Subjects }\end{array}$ & $\begin{array}{l}\text { Patients } \\
\text { with } \\
\text { Glaucoma }\end{array}$ \\
\hline $\begin{array}{l}\text { Cases fully characterized by sitting office-hour measurements } \\
\text { Cases fully characterized only by sitting office-hour measurements for } \\
\text { mean IOP and supine }+ \text { sitting office-hour measurements for IOP }\end{array}$ & 10 & 32 & 20 \\
\hline $\begin{array}{l}\text { fluctuation } \\
\text { Cases fully characterized only by supine }+ \text { sitting office-hour }\end{array}$ & 0 & 21 & 13 \\
\hline $\begin{array}{l}\text { measurements } \\
\text { Cases in which supine }+ \text { sitting office-hour measurements partially }\end{array}$ & 20 & 32 & 13 \\
\hline improved analysis & 10 & 10 & 23 \\
\hline Cases fully uncharacterized & 40 & 5 & 20 \\
\hline
\end{tabular}

Data are percentages. Full characterization: mean IOP, peak, and fluctuations, respectively, within $\pm 1, \pm 1, \pm 2 \mathrm{~mm} \mathrm{Hg}$ from the 24 -hour value. Full absence of characterization: mean IOP, peak, and fluctuations, respectively, outside $\pm 1, \pm 1, \pm 2 \mathrm{~mm} \mathrm{Hg}$ from the 24 -hour value. 
Moreover, the results in 24-hour studies from different groups are hardly comparable because of differences in the populations and in the methods used for data collection (settings, time points, and tonometers). In fact, 24-hour IOP fluctuation of our study $(7.3-7.5 \mathrm{~mm} \mathrm{Hg}$ in normal subjects, 9.3 $\mathrm{mm} \mathrm{Hg}$ in patients with glaucoma) are higher than in other 24-hour studies. (Liu et al. ${ }^{26}$ found a fluctuation of $\sim 5-5.5 \mathrm{~mm}$ $\mathrm{Hg}$ in young and elderly control subjects and of approximately $6 \mathrm{~mm} \mathrm{Hg}$ in patients with early, untreated glaucoma. ${ }^{28}$ )

In the present study, two different tonometers were used: the Goldmann tonometer, which is the clinical gold standard, but which is limited to use in the sitting position alone, and the handheld tonometer (TonoPen XL; Bio-Rad) for measurements in the supine position. Calculation of the habitual body position IOP curve therefore inherited a component related to the different accuracy and variability of the two tonometers (although TonoPen XL previously showed a good agreement with the Goldmann tonometer in eyes with normal corneas). ${ }^{29-31}$ This fact may represent a major limitation of our analysis, as it may have affected the absolute values of mean IOP and IOP fluctuation. On the other hand, the use of a single tonometer to collect IOP in all body positions (i.e., pneumatonometer, TonoPen XL, Perkins tonometer) would have implied the nonuse of the Goldmann tonometer and, hence, it would have strongly restricted the applicability of the message of our study to experimental settings, whereas its purpose was actually to suggest a strategy to extrapolate, in any clinical setting, data that are usually available only to a small number of centers worldwide. Moreover, we tested the agreement of measurements taken by the study operators with the two tonometers before the study, and it was good $(\kappa=0.82$, using $2 \mathrm{~mm} \mathrm{Hg}$ as a cutoff value, which is the interobserver variability generally accepted for Goldmann tonometry ${ }^{32}$ ).

Finally, the small number of young healthy subjects may have affected the significance of the statistical analyses. IOP fluctuation was expressed as the range and not as the standard deviation, as in previous studies. ${ }^{9}$ Although standard deviation represents a strong dispersion measure that is minimally affected by outliers, ranges were preferred in this study, as they are independent of the number of repetitions, which varied in the 24-hour curve (eight measurements) with respect to office hours (from four to nine measurements).

In conclusion, our analysis of office-hour IOP measurements highlights that sitting measurements alone provide inadequate information on peak, mean, and IOP fluctuation in a large number of subjects, whereas the combination of supine and sitting measurements gives a reasonable estimate of these parameters. We therefore recommend that supine and sitting IOP data be collected during office hours, at least in patients with abnormal tonometric functional behavior (i.e., unexplained progression) to reduce their need for 24-hour monitoring.

\section{References}

1. AGIS Investigators. Advanced Glaucoma Intervention Study (AGIS), 7: the relationship between control of intraocular pressure and visual field deterioration. Am J Ophthalmol. 2000;130:429440.

2. Higginbotham EJ, Gordon MO, Beiser JA, et al. Ocular Hypertension Treatment Study Group. The Ocular Hypertension Treatment Study: topical medication delays or prevents primary open-angle glaucoma in African American individuals. Arch Ophthalmol. 2004; 122:813-820.

3. Leske MC, Heijl A, Hussein M, Bengtsson B, Hyman L, Komaroff E. Early Manifest Glaucoma Trial Group. Factors for glaucoma progression and the effect of treatment: the early manifest glaucoma trial. Arch Ophthalmol. 2003;121:48-56.

4. Lichter PR, Musch DC, Gillespie BW, et al. Interim clinical outcomes in the Collaborative Initial Glaucoma Treatment Study com- paring initial treatment randomized to medications or surgery. Ophthalmology. 2001;108:1943-1953.

5. Asrani S, Zeimer R, Wilensky J, Gieser D, Vitale S, Lindenmuth K. Large diurnal fluctuations in intraocular pressure are an independent risk factor in patients with glaucoma. J Glaucoma. 2000;9: 134-142.

6. Bengtsson B, Leske MC, Hyman L, et al. Fluctuation of intraocular pressure and glaucoma progression in the Early Manifest Glaucoma Trial. Ophthalmology. 2007;114:205-209.

7. Caprioli J, Coleman AL. Intraocular pressure fluctuation: a risk factor for visual field progression at low intraocular pressures in the advanced glaucoma intervention study. Ophthalmology. 2008; 115:1123-1129.e3.

8. Medeiros FA, Weinreb RN, Zangwill LM, et al. Long-term intraocular pressure fluctuations and risk of conversion from ocular hypertension to glaucoma. Ophthalmology. 2008;115: 934-940.

9. Caprioli J. Intraocular pressure fluctuation: an independent risk factor for glaucoma? Arch Ophthalmol. 2007;125:1124-1125.

10. Barkana Y, Anis S, Liebmann J, Tello C, Ritch R. Clinical utility of intraocular pressure monitoring outside of normal office hours in patients with glaucoma. Arch Ophthalmol. 2006;124:793-797.

11. Hara $T$, Hara $T$, Tsuru $T$. Increase of peak intraocular pressure during sleep in reproduced diurnal changes by posture. Arch Ophthalmol. 2006;124:165-168.

12. Hughes E, Spry P, Diamond J. 24-Hour monitoring of intraocular pressure in glaucoma management: a retrospective review. J Glaucoma. 2003;12:232-236.

13. Tajunisah I, Reddy SC, Fathilah J. Diurnal variation of intraocular pressure in suspected glaucoma patients and their outcome. Graefes Arch Clin Exp Ophthalmol. 2007;245:1851-1857.

14. Blondeau P, Tétrault JP, Papamarkakis C. Diurnal variation of episcleral venous pressure in healthy patients: a pilot study. $J$ Glaucoma. 2001;10:18-24.

15. Meyer JH, Brandi-Dohrn J, Funk J. Twenty four hour blood pressure monitoring in normal tension glaucoma. Br J Ophthalmol. $1996 ; 80: 864-867$

16. Quaranta L, Gandolfo F, Turano R, et al. Effects of topical hypotensive drugs on circadian IOP, blood pressure, and calculated diastolic ocular perfusion pressure in patients with glaucoma. Invest Ophthalmol Vis Sci. 2006;47:2917-2923.

17. Orzalesi N, Rossetti L, Invernizzi T, Bottoli A, Autelitano A. Effect of timolol, latanoprost, and dorzolamide on circadian IOP in glaucoma or ocular hypertension. Invest Ophthalmol Vis Sci. 2000;41: 2566-2573.

18. Drance SM. Diurnal variation of intraocular pressure in treated glaucoma: significance in patients with chronic simple glaucoma. Arch Ophthalmol. 1963;70:302-311.

19. Liu JH, Bouligny RP, Kripke DF, et al. Nocturnal elevation of intraocular pressure is detectable in the sitting position. Invest Ophthalmol Vis Sci. 2003;44:4439-4442.

20. Nakakura S, Nomura Y, Ataka S, Shiraki K. Relation between office intraocular pressure and 24-hour intraocular pressure in patients with primary open-angle glaucoma treated with a combination of topical antiglaucoma eye drops. J Glaucoma. 2007; 16:201-204.

21. Mosaed S, Liu JH, Weinreb RN. Correlation between office and peak nocturnal intraocular pressures in healthy subjects and glaucoma patients. Am J Ophthalmol. 2005;139:320-324.

22. Orzalesi N, Rossetti L, Bottoli A, Fumagalli E, Fogagnolo P. The effect of latanoprost, brimonidine, and a fixed combination of timolol and dorzolamide on circadian intraocular pressure in patients with glaucoma or ocular hypertension. Arch Ophthalmol. 2003;121:453-457.

23. Orzalesi N, Rossetti L, Bottoli A, Fogagnolo P. Comparison of the effects of latanoprost, travoprost, and bimatoprost on circadian intraocular pressure in patients with glaucoma or ocular hypertension. Ophthalmology. 2006;113:239-246.

24. Tuulonen A, Airaksinen PJ. Initial glaucomatous optic disk and retinal nerve fiber layer abnormalities and their progression. $A m J$ Ophthalmol. 1991;111:485-490. 
25. Miglior S, Rossetti L, Brigatti L, et al. Reproducibility of retinal nerve fiber layer evaluation by dynamic scanning laser ophthalmoscopy. Am J Ophthalmol. 1994;118:16-23.

26. Liu JHK, Kripke DF, Hoffman RE, et al. Nocturnal elevation of intraocular pressure in young adults. Invest Ophthalmol Vis Sci. 1998;39:2707-2712.

27. Weinreb RN. Nocturnal rhythms of intraocular pressure. Arch Ophthalmol. 2006;124:269-270.

28. Liu JH, Zhang X, Kripke DF, Weinreb RN. Twenty-four-hour intraocular pressure pattern associated with early glaucomatous changes. Invest Ophthalmol Vis Sci. 2003;44:1586-1590.

29. Lim KS, Wickremasinghe SS, Cordeiro MF, Bunce C, Khaw PT.
Accuracy of intraocular pressure measurements in new zealand white rabbits. Invest Ophthalmol Vis Sci. 2005;46:2419-2423.

30. Abrams LS, Vitale S, Jampel HD. Comparison of three tonometers for measuring intraocular pressure in rabbits. Invest Ophthalmol Vis Sci. 1996;37:940-944.

31. Horowitz GS, Byles J, Lee J, D'Este C. Comparison of the Tono-Pen and Goldmann tonometer for measuring intraocular pressure in patients with glaucoma. Clin Experiment Ophthalmol. 2004;32: $584-589$.

32. Sudesh S, Moseley MJ, Thompson JR. Accuracy of Goldmann tonometry in clinical practice. Acta Ophthalmol Scand. 1993;71: 185-188. 